\title{
Energetics of running in top-level marathon runners from Kenya
}

\author{
Enrico Tam • Huber Rossi $\cdot$ Christian Moia • \\ Claudio Berardelli • Gabriele Rosa • \\ Carlo Capelli • Guido Ferretti
}

Received: 26 November 2011 / Accepted: 14 February 2012/Published online: 2 March 2012

(C) Springer-Verlag 2012

\begin{abstract}
On ten top-level Kenyan marathon runners (KA) plus nine European controls (EC, equivalent to KA), we measured maximal oxygen consumption $\left(\dot{V} \mathrm{O}_{2 \max }\right)$ and the energy cost of running $\left(C_{\mathrm{r}}\right)$ on track during training camps at moderate altitude, to better understand the KA dominance in the marathon. At each incremental running speed, steady-state oxygen consumption $\left(\dot{V} \mathrm{O}_{2}\right)$ was measured by telemetric metabolic cart, and lactate by electroenzymatic method. The speed requiring $\dot{V} \mathrm{O}_{2}=\dot{V} \mathrm{O}_{2 \max }$ provided the maximal aerobic velocity $\left(v_{\max }\right)$. The energy cost of running was calculated by dividing net $\dot{V} \mathrm{O}_{2}$ by the corresponding speed. The speed at lactate threshold $\left(v_{\Theta \mathrm{AN}}\right)$
\end{abstract}

Communicated by David C. Poole.

E. Tam · C. Moia - G. Ferretti

Département de Neurosciences Fondamentales,

Université de Genève, Geneva, Switzerland

E. Tam

Facoltà di Scienze Motorie, Università di Bologna, Bologna, Italy

H. Rossi · C. Berardelli · G. Rosa

Marathon Sport Medical Center, Brescia, Italy

C. Capelli

Dipartimento di Scienze Neurologiche, Neuropsicologiche, Morfologiche e Motorie, Facoltà di Scienze Motorie,

Università di Verona, Verona, Italy

G. Ferretti

Dipartimento di Scienze Biomediche e Biotecnologie,

Facoltà di Medicina, Università di Brescia, Brescia, Italy

G. Ferretti $(\bowtie)$

Département des Neurosciences Fondamentales, Centre Médical Universitaire, 1 rue Michel Servet, 1211 Geneva 4, Switzerland e-mail: Guido.Ferretti@unige.ch was computed from individual Lâb versus speed curves. The sustainable $\dot{V} \mathrm{O}_{2 \max }$ fraction $\left(F_{\mathrm{d}}\right)$ at $v_{\Theta \mathrm{AN}}\left(F_{\mathrm{\Theta AN}}\right)$ was computed dividing $v_{\Theta A N}$ by $v_{\max }$. The $F_{\mathrm{d}}$ for the marathon $\left(F_{\mathrm{mar}}\right)$ was determined as $F_{\mathrm{mar}}=0.92 F_{\text {@AN }}$. Overall, $\dot{V} \mathrm{O}_{2 \max }\left(64.9 \pm 5.8\right.$ vs. $\left.63.9 \pm 3.7 \mathrm{ml} \mathrm{kg}^{-1} \min ^{-1}\right), v_{\max }$ $\left(5.55 \pm 0.30\right.$ vs. $\left.5.41 \pm 0.29 \mathrm{~m} \mathrm{~s}^{-1}\right)$ and $C_{\mathrm{r}}(3.64 \pm 0.28$ vs. $3.63 \pm 0.31 \mathrm{~J} \mathrm{~kg}^{-1} \mathrm{~m}^{-1}$ ) resulted the same in $\mathrm{KA}$ as in EC. In both groups, $C_{\mathrm{r}}$ increased linearly with the square of speed. $F_{\Theta A N}$ was $0.896 \pm 0.054$ in KA and $0.909 \pm 0.068$ in $\mathrm{EC} ; F_{\mathrm{mar}}$ was $0.825 \pm 0.050$ in KA and $0.836 \pm 0.062$ in EC (NS). Accounting for altitude, running speed predictions from present data are close to actual running performances, if $F_{\Theta \mathrm{AN}}$ instead of $F_{\mathrm{mar}}$ is taken as index of $F_{\mathrm{d}}$. In conclusion, both $\mathrm{KA}$ and EC did not have a very high $\dot{V} \mathrm{O}_{2 \max }$, but had extremely high $F_{\mathrm{d}}$, and low $C_{\mathrm{r}}$, equal between them. The dominance of KA over EC cannot be explained on energetic grounds.

Keywords Maximal oxygen consumption - Energy cost . Running performance $\cdot$ Ethnic groups $\cdot$ Altitude

\section{Introduction}

A remarkable evolution in marathon running performance has occurred in recent years. In 1990, the 50th best performer of the year ran in $2 \mathrm{~h} 13 \mathrm{~min}$ and $1 \mathrm{~s}$, implying an average running speed over the distance of $5.287 \mathrm{~m} \mathrm{~s}^{-1}$ or $19.03 \mathrm{~km} \mathrm{~h}^{-1}$ (source: http://digilander.libero.it/atletica2/ Stagionali/WRL/1990/Mar). The equivalent performance in 2010 was $2 \mathrm{~h} 8 \mathrm{~min}$ and $25 \mathrm{~s}$, for an average running speed of $5.476 \mathrm{~m} \mathrm{~s}^{-1}$ or $19.72 \mathrm{~km} \mathrm{~h}^{-1}$ (source: http:// www.iaaf.org/statistics/toplists), representing a $3.58 \%$ improvement with respect to 20 years earlier. Impressively enough, this unusual performance improvement has been 
largely due to marathon runners from Kenya. In 1990, there was only one athlete from Kenya in the top 50 list, and he was a Kikuyu. This number never stopped increasing ever since. In 2010, there were 30 Kenyans in the top 50 performers in the marathon, and 108 in the top 200. Similar tendencies can also be reckoned for the half-marathon performance.

Most of the current marathon runners from Kenya belong to the same ethnic group, the Kalenjin. Of the 30 Kenyans in the 2010 top 50 list, 29 were Kalenjin and 1 Kikuyu. The Kalenjins constitute some 3.5 million individuals, divided into 12 tribes that have been dwelling for centuries on the highlands of the Rift Valley, in the western part of Kenya. For more details on the demography and social geography of the Kalenjin tribes, see Larsen (2003). The question is how such an extraordinary achievement by such a small-sized population could take place. Several aspects were looked at, including population genetics (Larsen 2003, 2004; Yang et al. 2007), food intake (Onywera et al. 2004), demography and social organization (Larsen 2003; Onywera et al. 2006), and hematology (Prommer et al. 2010). In the field of exercise physiology, maximal oxygen consumption, lactate threshold and running economy (Billat et al. 2003; Larsen et al. 2004; Saltin et al. 1995b), muscle morphology and muscle fiber typing (Saltin et al. 1995a) were investigated. These studies, however, provided only limited answers to the above question.

Most of previous physiological studies on Kenyan runners were not carried out on top athletes, but on either medium-level or junior athletes and this jeopardized the possibility of identifying differences with respect to athletes from other ethnic groups. This was the first study to be carried out on real top marathon runners: the studied Kalenjin included Martin Lel, multiple winner of London and New York City marathons, and Sammy Korir, who in Berlin ended one second apart from the world record; the control group included Stefano Baldini from Italy, winner of the Olympic marathon in Athens 2004, and Viktor Röthlin from Switzerland, the current European champion.

The maximal velocity that a long-distance runner can sustain over a given distance $\left(v_{\mathrm{d}}\right)$ is equal to:

$v_{\mathrm{d}}=\frac{\dot{E}_{\max }}{C_{\mathrm{r}}}=\frac{F \mathrm{~d} \times \dot{V} \mathrm{O}_{2 \max }}{C_{\mathrm{r}}}$

where $C_{\mathrm{r}}$ is the energy cost of running (the physical parameter quantifying running economy), $\dot{E}_{\max }$ is the maximal sustainable metabolic power, $\dot{V} \mathrm{O}_{2 \max }$ is the maximal oxygen consumption and $F_{\mathrm{d}}$ is the fraction of $\dot{V} \mathrm{O}_{2 \max }$ that can be sustained over the race distance. When $\dot{E}_{\max }=\dot{V} \mathrm{O}_{2 \max }$, then $F_{\mathrm{d}}=1$; when $\dot{E}_{\max }<\dot{V} \mathrm{O}_{2 \max }$, then $F_{\mathrm{d}}<1$. The latter is the case for the marathon, in which $F_{\mathrm{d}}$ is somehow related to the so-called lactate threshold speed (Ferretti et al. 2011), which Helgerud et al. (1990) defined as the highest speed at which, during a 20-min continuous exercise, blood lactate concentration increases by less than $1 \mathrm{mM}$ in the last $15 \mathrm{~min}$. Because of Eq. 1, the measurement of $\dot{V} \mathrm{O}_{2 \max }$ and $C_{\mathrm{r}}$ and the estimate of $F_{\mathrm{d}}$ is first source of information on potential differences on the sustainable marathon speed between Kalenjin and Caucasians (di Prampero 1986; Ferretti et al. 2011). Other factors may be called upon for a deeper physiological understanding of the phenomenon of Kenyan runners, but if physiological differences exist between Kalenjin runners and runners from other ethnic groups, they can only translate into visible differences in the three terms of the right branch of Eq. 1.

The aim of this study was thus to measure $\dot{V} \mathrm{O}_{2 \max }, C_{\mathrm{r}}$ and estimate $F_{\mathrm{d}}$ in a set of top-level marathon runners issued from the Kalenjin ethnic group and compare them with the data obtained on a group of top-level Caucasian athletes. The hypothesis was that the predominance of the Kalenjin in the marathon could be explained by differences in the three terms of Eq. 1 with respect to their Caucasian competitors.

\section{Methods}

\section{Subjects}

Ten Kalenjin marathon runners (KA) participated in the study. They all had a best performance in the marathon of less than $2 \mathrm{~h}$ and $9 \mathrm{~min}$. A control group of nine top European athletes (European controls, EC) was also enrolled, with similar performances to those of KA. The physical characteristics of KA and EC are reported in Table 1, together with the best performances in the marathon and the semi marathon in the 2 years that preceded and followed the performance of the tests. The two groups did not differ among them, except for the fact that EC were significantly older than KA. Body mass was strictly the same (1.7 kg difference, $p=0.482$ ). Nevertheless, KA had significantly better performances on both the marathon and the half-marathon than EC, although only four EC athletes had a performance on the marathon.

The athletes were investigated outside the competition period, during winter or summer training stages. This implies that all experiments were carried out at altitude, in winter at Eldoret, Kenya (altitude 2,000 m, inspired oxygen pressure $\left.\left(\mathrm{PIO}_{2}\right), 113.2 \pm 0.6 \mathrm{mmHg}\right)$, in summer either at Saint Moritz, Switzerland (altitude $1,800 \mathrm{~m}, \mathrm{PiO}_{2}$ $116.7 \pm 0.5 \mathrm{mmHg}$ ) or at Ortisei, Italy (altitude $1,300 \mathrm{~m}$, $\mathrm{PIO}_{2} 127.3 \pm 0.5 \mathrm{mmHg}$ ). 
Table 1 Basic characteristics of the subjects and their performances on the marathon and the half-marathon

\begin{tabular}{|c|c|c|c|c|c|c|c|}
\hline Subjects & $\begin{array}{l}\text { Age } \\
\text { (yy) }\end{array}$ & $\begin{array}{l}\text { Height } \\
(\mathrm{cm})\end{array}$ & $\begin{array}{l}\text { Body } \\
\text { mass }(\mathrm{kg})\end{array}$ & 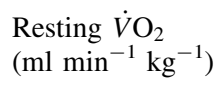 & $\begin{array}{l}\text { Resting fh } \\
\left(\min ^{-1}\right)\end{array}$ & $\begin{array}{l}\text { Marathon } \\
\text { time (s) }\end{array}$ & $\begin{array}{l}\text { Half-marathon } \\
\text { time (s) }\end{array}$ \\
\hline \multicolumn{8}{|l|}{ KA } \\
\hline Mean & 29 & 172 & 59.4 & 5.7 & 59 & 7,637 & 3,640 \\
\hline SD & 4 & 7 & 5.8 & 1.4 & 4 & 87 & 31 \\
\hline \multicolumn{8}{|l|}{ EC } \\
\hline Mean & 33 & 175 & 61.1 & 6.7 & 65 & $7,704^{\mathrm{a}}$ & 3,717 \\
\hline SD & 4 & 5 & 4.5 & 2.3 & 11 & 75 & 47 \\
\hline
\end{tabular}

Concerning performances, as expressed in IAAF official timing rules, the average marathon times corresponded to $2 \mathrm{~h} 7 \mathrm{~min}$ and $17 \mathrm{~s}$ (SD $1 \mathrm{~min}$ $27 \mathrm{~s}$ ) in KA, and $2 \mathrm{~h} 8 \mathrm{~min} 24 \mathrm{~s}$ (SD $1 \mathrm{~min} 15 \mathrm{~s}$ ) in EC, whereas the average half-marathon times corresponded to $60 \mathrm{~min}$ and $40 \mathrm{~s}$ (SD $31 \mathrm{~s}$ ) in $\mathrm{KA}$ and $61 \mathrm{~min}$ and $57 \mathrm{~s}$ (SD $47 \mathrm{~s})$ in EC

$\dot{V} \mathrm{O}_{2}$ oxygen consumption, $f h$ heart rate, $K A$ top-level Kalenjins $(n=10), E C$ European controls $(n=9)$

a $n=4$

Study designs and methods were approved by the ethical committee of the local health agency of Brescia, Italy, where Rosa Associati, the athletes managing company, is located. All the subjects were informed about the aims of the investigation and the methods applied in the experiments, and they all signed a written informed consent form.

\section{Protocol}

This was a field study and the experiments were performed on an athletic camp. In Eldoret, we operated at the Kipchoge Keyno Stadium, whose track is in red clay. In Europe, experiments were performed on training camps, whose track was covered with synthetic material. The length of the track on the inner circle was measured and in all cases resulted to be within $2 \mathrm{~m}$ from the official length of $400 \mathrm{~m}$. Starting from the goal line, plastic cones were positioned $50 \mathrm{~m}$ apart, to give a precise reference of the distance covered. An investigator, who cycled $10 \mathrm{~m}$ ahead of the athlete following the rhythm imposed by a metronome, paced the running velocity. The frequency of the metronome at each speed was set in such a way as to have a beep each time the bicycle had to pass beside a cone. The distance between the bicycle and the athlete, who ran in the innermost track, was such as to avoid any reduction of the air resistance encountered by the athletes while running.

A progressive step protocol was applied. Starting from a velocity of $12 \mathrm{~km} \mathrm{~h}^{-1}$, the velocity was progressively increased by steps of $2 \mathrm{~km} \mathrm{~h}^{-1}$, up to $20 \mathrm{~km} \mathrm{~h}^{-1}$. Each step lasted $4 \mathrm{~min}$. Successive steps were separated by 5min intervals, during which micro blood samples were taken from an earlobe for the measurement of blood lactate concentration. In most cases, the athlete sustained the $20 \mathrm{~km} \mathrm{~h}^{-1}$ step without signs of exhaustion. If this was so, then a final step was performed, consisting of an all-out trial over the 800-m distance. This effort was slightly supramaximal for all athletes. At the end of this last trial, peak blood lactate concentration (Lâb $\hat{b}_{b}$ was determined with micro blood samples taken at min 1, 3 and 5 during recovery. Arterial oxygen saturation $\left(\mathrm{SaO}_{2}\right)$ was also measured before and immediately after the end of the test.

\section{Measurements}

Oxygen consumption $\left(\dot{V} \mathrm{O}_{2}\right)$ at the exercise steady state was determined by means of a portable telemetric metabolic cart (Cosmed K4, Rome, Italy) at rest and during each running trial. The system comprised a turbine flowmeter (instantaneous flow between 0.03 and $20 \mathrm{l} \mathrm{s}^{-1}$; precision $\pm 2 \%$ ), a zirconium oxygen analyzer (precision $\pm 0.02 \%$, response time $<150 \mathrm{~m} \mathrm{~s}$ ) and an infrared carbon dioxide analyzer (precision $\pm 0.01 \%$, response time $<150 \mathrm{~m} \mathrm{~s}$ ). The metabolic system was calibrated before and after each experimental session by means of certified gas mixtures and a 3-1 syringe (Hans Rudolph, Kansas City, MO, USA). $R$ was calculated from $\dot{V} \mathrm{CO}_{2}$ and $\dot{V} \mathrm{O}_{2}$ data. Heart rate was measured continuously by a cardiometer (Polar, Finland). Peak blood lactate concentration was measured by an electro-enzymatic method (Lactate Pro, Biomedic Labs, USA). Arterial oxygen saturation was measured by infrared spectrometry (Siemens $\mathrm{MicrO}_{2}$, Denvers, MA, USA).

The individual $\dot{V} \mathrm{O}_{2 \max }$ was determined from the plateau attained by the $\dot{V} \mathrm{O}_{2}$ versus speed relationship above a given speed. This plateau was observed in all tests. The corresponding maximal aerobic velocity $\left(v_{\max }\right)$ was calculated as the minimal speed requiring a $\dot{V} \mathrm{O}_{2}$ equal to $\dot{V} \mathrm{O}_{2 \max }$, or, in other terms, as the velocity at the crossing of the $\dot{V} \mathrm{O}_{2 \text { max }}$ plateau with the $\dot{V} \mathrm{O}_{2}$ versus speed line. $C_{\mathrm{r}}$ was computed at all speeds lower than $v_{\max }$ (submaximal speeds) as the ratio between the net (measured minus upright resting) steady state $\dot{V} \mathrm{O}_{2}$ at each speed and the corresponding speed. The speed at the lactate threshold ( $\left.v_{\Theta A N}\right)$ was computed from the Lâ $\hat{b}_{\mathrm{b}}$ versus speed curves, 
with the same procedure used by Helgerud (1994). The sustainable fraction of $\dot{V} \mathrm{O}_{2 \max }$ at $v_{\text {QAN }}\left(F_{\text {QAN }}\right)$ was computed as the ratio of $v_{\Theta A N}$ to $v_{\max }$. The $F_{\mathrm{d}}$ for the marathon $\left(F_{\mathrm{mar}}\right)$ was then determined as (Helgerud 1994):

$F_{\text {mar }}=0.92 F_{\Theta \mathrm{AN}}$

Statistics

Mean values are reported along with their standard deviations (SD). Data comparison among groups was done by means of a student $t$ test for unpaired observations. Although the level of significance was formally set at $p<0.05$ (two-tailed test), actual $p$ values are reported. Concerning $C_{\mathrm{r}}$, comparison of $C_{\mathrm{r}}$ changes with increasing speed within each group was done by means of a one-way analysis of variance for repeated measures. When applicable, a Tukey post hoc test was used to locate significant differences. The level of significance was set at $p<0.05$ (two-tailed test). Linear regression equations were computed with the least-squares method. The slope was considered significant when $p<0.05$. Slopes and y-intercepts were compared by means of analysis of covariance (Kleinbaum et al. 1987). In figures, values are given as mean and standard deviation, whereas lines are regression lines computed on individual data.

\section{Results}

The $\dot{V} \mathrm{O}_{2 \max }$ is reported in Table 2 for both KA and EC, together with the related parameters. $p$ values indicate that $\dot{V} \mathrm{O}_{2 \max }$ was indeed the same in $\mathrm{KA}$ as in $\mathrm{EC}$, as were all other reported parameters, despite the observed significant differences in marathon performance. Of course, a tendency toward lower $\dot{V} \mathrm{O}_{2 \max }$ values at Eldoret or St. Moritz than at Ortisei was observed, for both KA $(63.1 \pm 6.9$ vs. $67.5 \pm$ $\left.2.6 \mathrm{ml} \mathrm{kg}^{-1} \mathrm{~min}^{-1}\right)$ and EC $(62.3 \pm 5.2$ vs. $65.2 \pm 1.6$ $\mathrm{ml} \mathrm{kg}{ }^{-1} \min ^{-1}$ ). The mean $C_{\mathrm{r}}$ was $3.64 \pm 0.28 \mathrm{~J} \mathrm{~kg}^{-1} \mathrm{~m}^{-1}$ $\left(174 \pm 13 \mathrm{ml} \mathrm{kg}^{-1} \mathrm{~km}^{-1}\right)$ in KA and $3.63 \pm 0.31 \mathrm{~J}$ $\mathrm{kg}^{-1} \mathrm{~m}^{-1}\left(174 \pm 15 \mathrm{ml} \mathrm{kg}^{-1} \mathrm{~km}^{-1}\right)$ in EC, again practically the same in the two groups ( $p=0.963$ ).

However, when the effects of speed on $C_{\mathrm{r}}$ is analyzed, as in Table 3, it appears that the $C_{\mathrm{r}}$ at the speed of $18 \mathrm{~km} \mathrm{~h}^{-1}$ was significantly higher than at the speed of $12 \mathrm{~km} \mathrm{~h}^{-1}$ in both groups ( $p=0.046$ for KA and 0.042 for EC), although no differences between groups were observed at any speed. If we plot $C_{\mathrm{r}}$ as a function of the square of submaximal running speeds, as in Fig. 1, significant linear relationships are found for each group. The two regression lines, also reported on the same figure, had no significant differences in slopes and y-intercepts, partly because of inter-individual variability within groups (coefficient of variations for $C_{\mathrm{r}} 7.7 \%$ in $\mathrm{KA}$ and $8.6 \%$ in $\mathrm{EC}$ ). The y-intercepts, corresponding to the non-aerodynamic component of $C_{\mathrm{r}}\left(C_{\mathrm{na}}\right)$ were indeed very close, equal to $3.288 \mathrm{~J} \mathrm{~kg}^{-1} \mathrm{~m}^{-1}$ in $\mathrm{KA}$ and $3.234 \mathrm{~J} \mathrm{~kg}^{-1} \mathrm{~m}^{-1}$ in EC, as were the slopes, corresponding to the aerodynamic constant $k$, which were equal to 0.0180 and $0.0191 \mathrm{~J} \mathrm{~s}^{2} \mathrm{~kg}^{-1} \mathrm{~m}^{-3}$ in KA and EC, respectively.

The $v_{\theta \mathrm{AN}}$ was $4.96 \pm 0.15 \mathrm{~m} \mathrm{~s}^{-1}$ in $\mathrm{KA}$ and $4.92 \pm 0.43 \mathrm{~m} \mathrm{~s}^{-1}$ in EC $(p=0.774)$. As a consequence, the $F_{\theta \text { AN }}$ turned out to be equal to $0.896 \pm 0.055$ in KA and $0.909 \pm 0.068$ in EC $(p=0.653)$, indicating that EC and KA really had almost equal $F_{\theta \mathrm{AN}}$. The $F_{\mathrm{mar}}$ was equal to $0.825 \pm 0.050$ and $0.836 \pm 0.062$, in $\mathrm{KA}$ and $\mathrm{EC}$, respectively (Table 4 ).

The combination of individual $\dot{V} \mathrm{O}_{2 \max }, C_{\mathrm{r}}$ at the speed of $18 \mathrm{~km} \mathrm{~h}^{-1}$ (note that $C_{\mathrm{r}}$ varies with speed) and $F_{\text {mar }}$ yielded a prediction of mean sustainable running speed in the marathon, at the altitudes at which the study was carried out, of $4.561 \pm 0.246 \mathrm{~m} \mathrm{~s}^{-1}$ in $\mathrm{KA}$ and $4.568 \pm 0.578 \mathrm{~m} \mathrm{~s}^{-1}$ in EC $(p=0.972)$.

\section{Discussion}

According to Eq. 1, three factors determine the maximal sustainable speed during a marathon: the $\dot{V} \mathrm{O}_{2 \max }$, its

Table 2 Maximal oxygen consumption and related parameters

\begin{tabular}{|c|c|c|c|c|c|c|c|c|}
\hline Subjects & $\dot{V} \mathrm{O}_{2 \max }\left(1 \min ^{-1}\right)$ & $\dot{V} \mathrm{O}_{2 \max }\left(\mathrm{ml} \mathrm{min} \min ^{-1} \mathrm{~kg}^{-1}\right)$ & {$[\mathrm{La}]_{\max }(\mathrm{mM})$} & $v_{\max }\left(\mathrm{m} \mathrm{s}^{-1}\right)$ & $v_{\max }\left(\mathrm{km} \mathrm{h}^{-1}\right)$ & $\mathrm{fh}_{\max }\left(\min ^{-1}\right)$ & $R$ & $\overline{\mathrm{SaO}_{2}}$ \\
\hline \multicolumn{9}{|l|}{ KA } \\
\hline Mean & 3.83 & 64.9 & 8.63 & 5.55 & 20.0 & 181 & 1.09 & 0.84 \\
\hline SD & 0.36 & 5.8 & 3.75 & 0.30 & 1.1 & 9 & 0.11 & 0.07 \\
\hline \multicolumn{9}{|l|}{$\mathrm{EC}$} \\
\hline Mean & 3.90 & 63.9 & 9.56 & 5.41 & 19.5 & 174 & 1.06 & 0.88 \\
\hline SD & 0.35 & 3.7 & 4.22 & 0.29 & 1.0 & 9 & 0.07 & 0.05 \\
\hline$p$ & 0.698 & 0.660 & 0.617 & 0.332 & 0.332 & 0.111 & 0.474 & 0.107 \\
\hline
\end{tabular}

$\dot{V} O_{2 \max }$ maximal oxygen consumption, $[\mathrm{La}]_{\max }$ maximal blood lactate concentration, $f h_{\max }$ maximal heart rate, $R$ gas exchange ratio at maximal exercise, $\mathrm{SaO}_{2}$ arterial oxygen saturation, $K A$ top-level Kalenjins $(n=10), E C$ European controls $(n=9)$ 
Table 3 Energy cost of running $\left(C_{\mathrm{r}}\right)$ (mean and standard deviations) at the various investigated speeds $(v)$

\begin{tabular}{|c|c|c|c|c|c|}
\hline \multirow[t]{2}{*}{$V\left(\mathrm{~km} \mathrm{~h}^{-1}\right)$} & \multicolumn{2}{|c|}{$C_{\mathrm{r}}\left(\mathrm{J} \mathrm{kg}^{-1} \mathrm{~m}^{-1}\right)$} & \multicolumn{2}{|c|}{$C_{\mathrm{r}}\left(\mathrm{ml} \mathrm{kg}^{-1} \mathrm{~km}^{-1}\right)$} & \multirow[t]{2}{*}{$p$} \\
\hline & KA & $\mathrm{EC}$ & KA & $\mathrm{EC}$ & \\
\hline \multicolumn{6}{|l|}{12} \\
\hline Mean & 3.48 & 3.44 & 167 & 165 & 0.766 \\
\hline SD & 0.26 & 0.28 & 13 & 14 & \\
\hline \multicolumn{6}{|l|}{14} \\
\hline Mean & 3.56 & 3.53 & 170 & 169 & 0.853 \\
\hline SD & 0.30 & 0.29 & 15 & 14 & \\
\hline \multicolumn{6}{|l|}{16} \\
\hline Mean & 3.67 & 3.61 & 176 & 173 & 0.748 \\
\hline SD & 0.38 & 0.41 & 18 & 20 & \\
\hline \multicolumn{6}{|l|}{18} \\
\hline Mean & 3.72 & 3.71 & 178 & 178 & 0.943 \\
\hline SD & 0.34 & 0.34 & 16 & 16 & \\
\hline
\end{tabular}

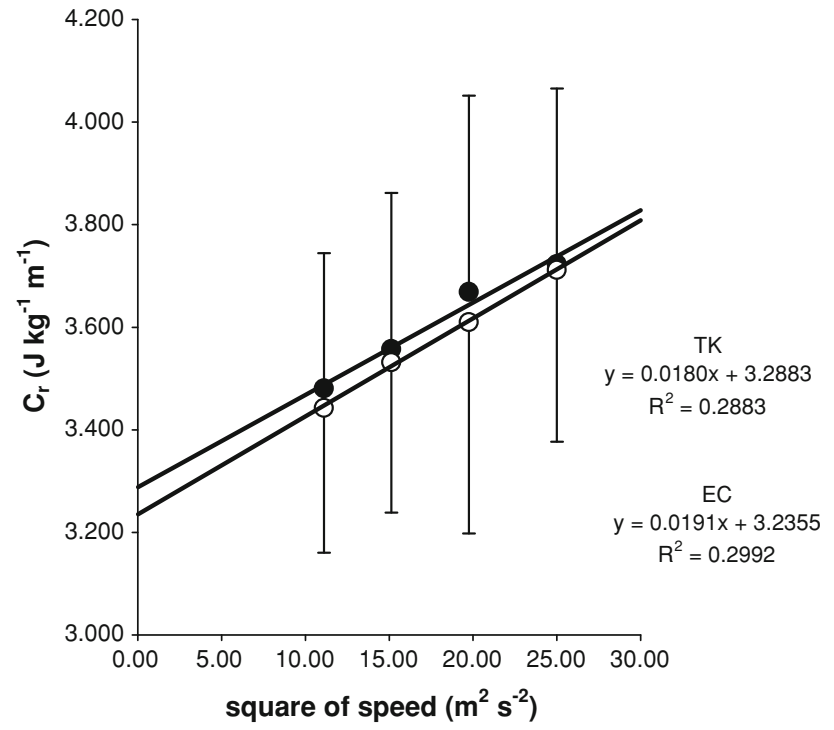

Fig. 1 Mean values of the energy cost of running $\left(C_{\mathrm{r}}\right)$ as a function of the square of speed. Data are given as mean and standard deviation. Regressions have been calculated on individual data. Filled circle top-level Kalenjin (KA), open circle European controls (EC)

sustainable fraction and $C_{\mathrm{r}}$ (di Prampero 1986; Ferretti et al. 2011). All these factors were determined on KA and EC. This was the first study in which the energetics of running in top-level Kenyan marathon runners was investigated. In fact, the best performances of the KA group were such as to place all the members of this group within the top 50 list of year 2010 or the top 200 best performances of all time in the marathon, according to the records of the International Association of Athletic Federations (see http://www.iaaf.org/statistics/toplists). None of the previous studies of the energetics of running in
Table 4 Prediction of marathon average speed at sea level

\begin{tabular}{|c|c|c|}
\hline Sea level & KA & $\mathrm{EC}$ \\
\hline \multicolumn{3}{|c|}{$\dot{V} \mathrm{O}_{2 \max }\left(\mathrm{ml} \mathrm{min} \min ^{-1} \mathrm{~kg}^{-1}\right)$} \\
\hline Mean & 69.1 & 67.9 \\
\hline $\mathrm{SD}$ & 6.0 & 3.7 \\
\hline \multicolumn{3}{|c|}{$C_{\mathrm{r}}$ at $18 \mathrm{~km} \mathrm{~h}^{-1}\left(\mathrm{~J} \mathrm{~m}^{-1} \mathrm{~kg}^{-1}\right)$} \\
\hline Mean & 3.83 & 3.83 \\
\hline SD & 0.35 & 0.32 \\
\hline \multicolumn{3}{|l|}{$F_{\text {mar }}$} \\
\hline Mean & 0.825 & 0.836 \\
\hline SD & 0.050 & 0.062 \\
\hline \multicolumn{3}{|l|}{$F_{\Theta \mathrm{AN}}$} \\
\hline Mean & 0.896 & 0.909 \\
\hline $\mathrm{SD}$ & 0.054 & 0.068 \\
\hline \multicolumn{3}{|l|}{$F_{\mathrm{d} \text {, actual }}$} \\
\hline Mean & 0.933 & 0.919 \\
\hline $\mathrm{SD}$ & 0.058 & 0.050 \\
\hline \multicolumn{3}{|c|}{$v\left(F_{\mathrm{mar}}\right)\left(\mathrm{km} \mathrm{h}^{-1}\right)$} \\
\hline Mean & 17.13 & 16.85 \\
\hline $\mathrm{SD}$ & 0.95 & 1.92 \\
\hline \multicolumn{3}{|c|}{$v\left(F_{\mathrm{EAN}}\right)\left(\mathrm{km} \mathrm{h}^{-1}\right)$} \\
\hline Mean & 18.62 & 18.31 \\
\hline $\mathrm{SD}$ & 1.03 & 2.09 \\
\hline \multicolumn{3}{|c|}{$v\left(F_{\mathrm{d}, \text { actual }}\right)\left(\mathrm{km} \mathrm{h}^{-1}\right)$} \\
\hline Mean & 19.39 & 19.36 \\
\hline $\mathrm{SD}$ & 1.02 & 0.77 \\
\hline \multicolumn{3}{|c|}{$v_{\text {record }}\left(\mathrm{km} \mathrm{h}^{-1}\right)$} \\
\hline Mean & 19.89 & $19.72^{*}$ \\
\hline SD & 0.23 & 0.19 \\
\hline
\end{tabular}

$\dot{V} \mathrm{O}_{2 \max }$ estimated maximal oxygen consumption at sea level, $C_{r}$ energy cost of running, $F_{\text {mar }}$ sustainable fraction of maximal aerobic speed calculated according to Helgerud et al. 1990, $F_{\text {@AN }}$ sustainable fraction of $\dot{V} \mathrm{O}_{2 \max }$ calculated after the speed at the lactate threshold, $F_{\mathrm{d}}$ actual, sustainable fraction of maximal aerobic speed calculated after the average speed sustained during the best performance marathon, $v$ velocity, $v_{\text {record }}$ average speed attained during best performance marathon by the investigated athletes, $K A$ top-level Kalenjins, $E C$ European controls $(* n=4$ for this group)

Kenyan long-distance runners could be carried out on athletes of similar level to the present ones. In the past, only adolescent or junior athletes, or runners of a lesser level, could be studied (Billat et al. 2003; Larsen et al. 2004; Saltin et al. 1995b). These studies revealed no differences with respect to their European controls. The suspicion existed, however, that energetic differences might have appeared when real top-level athletes were studied. The present results showed that this was not so, since no differences between KA and EC were found for any of the investigated parameters. As a consequence, equal predicted marathon speeds were obtained for both KA and EC at the altitudes where this study was carried out. These results 
show that, contrary to the tested hypothesis, the supremacy of Kenyan runners over Caucasians in the marathon is not due to differences in the energetics of running. Yet, we demonstrated a clear effect of speed on $C_{\mathrm{r}}$ in both KA and EC, which we attributed to an effect of speed on the energy cost against aerodynamic forces, $C_{\mathrm{a}}$. This effect was strictly the same in KA and EC. The three parameters that determine the sustainable mean running speed of a marathon are discussed separately, before putting them together in an attempt at predicting the marathon speed at sea level and compare it with the actual mean speed during competition.

\section{Maximal oxygen consumption}

The relatively low $\dot{V} \mathrm{O}_{2 \max }$ values were obviously a consequence of the altitude at which the tests were carried out. Due to logistic constraints, tests had to be made at two different altitudes, so at two inspired $\mathrm{PO}_{2}$ values, both lower than at sea level, where most marathons take place. This may be viewed as a limitation of our study. The mean $\dot{V} \mathrm{O}_{2 \max }$ value reported in Table 2 accounts for the two altitudes. Luckily enough, the fraction of athletes investigated at 2,000 $\mathrm{m}$ was the same in the two groups, which made group comparison possible. An estimate of the equivalent $\dot{V} \mathrm{O}_{2 \max }$ at sea level requires deciding about the occurrence of arterial oxygen desaturation at maximal exercise (Dempsey effect, Dempsey et al. 1984) in these athletes. This occurrence is unpredictable from the measured $\mathrm{SaO}_{2}$. For the sake of simplicity, we assumed that the present subjects were not affected by the Dempsey effect. Based on this assumption, the individual $\dot{V} \mathrm{O}_{2 \max }$ values at sea level could be calculated from the characteristics of the classical curve describing the $\dot{V} \mathrm{O}_{2 \max }$ decrease at altitude (Ferretti 1990), considering the actual altitude at which each test was done. Then the corresponding $\mathrm{SaO}_{2}$ values at sea level were estimated after the linear $\dot{V} \mathrm{O}_{2 \max }$ versus $\mathrm{SaO}_{2}$ relationship reported by Ferretti et al. (1997).

At sea level, estimated $\dot{V} \mathrm{O}_{2 \max }$ turned out equal to $69.1 \pm 6.0 \mathrm{ml} \mathrm{min}{ }^{-1} \mathrm{~kg}^{-1}$ in $\mathrm{KA}$ and $68.7 \pm 4.0$ $\mathrm{ml} \mathrm{min}{ }^{-1} \mathrm{~kg}^{-1}$ in EC $(p=0.841)$. These $\dot{V} \mathrm{O}_{2 \max }$ values were associated with $v_{\max }$ values at sea level of $5.94 \pm 0.33 \mathrm{~m} \mathrm{~s}^{-1}$ in KA and $5.78 \pm 0.33 \mathrm{~m} \mathrm{~s}^{-1}$ in EC ( $p=0.318)$. These sea-level $\dot{V} \mathrm{O}_{2 \max }$ values were coupled with estimated $\mathrm{SaO}_{2}$ values at maximal exercise of $0.89 \pm 0.08$ and $0.94 \pm 0.05$, in KA and EC, respectively $(p=0.173)$. The estimated $\mathrm{SaO}_{2}$ values of KA are in the range of what Dempsey and Wagner (1999) define as moderate exercise-induced arterial hypoxemia, suggesting that our assumption might have been partially wrong. Nevertheless, in view of the moderate altitude at which the tests were made, the hypothetical error introduced in this estimate would be, practically speaking, negligible. In fact, only slightly higher sea-level $\dot{V} \mathrm{O}_{2 \max }$ values would have been obtained by using the linear relationship that Wehrlin and Hallén (2006) established for desaturating athletes. Moreover, the mean $\mathrm{SaO}_{2}$ value of $\mathrm{KA}$ is affected by the data of two athletes, who were remarkably hypoxemic at maximal exercise (their $\mathrm{SaO}_{2}$ values were 0.71 and 0.74 at the end of the test, carried out in Eldoret). Saltin et al. (1995b) found a $16.6 \%$ higher $\dot{V} \mathrm{O}_{2 \max }$ at sea level than at $2,000 \mathrm{~m}$ in a group of young medium-level Kalenjin runners, suggestive of severe exercise-induced arterial hypoxemia in those subjects. This was not the case for the present KA: a $16.6 \%$ higher $\dot{V} \mathrm{O}_{2 \max }$ at sea level would have implied $\mathrm{SaO}_{2}$ values around 1.0, if not above, for the present subjects, a preposterous situation indeed.

The estimated $\dot{V} \mathrm{O}_{2 \max }$ values at sea level are elevated, but not as high as one would expect. They can conveniently be compared with those of Coetzer et al. (1993), who found similar $\dot{V} \mathrm{O}_{2 \max }$ values than the present ones in a group of high-level South-African long-distance runners investigated at sea level. Yet, they appear lower than those found by others on Kenyan runners of lesser level than the present ones (Billat et al. 2003; Saltin et al. 1995b). Even higher $\dot{V} \mathrm{O}_{2 \max }$ values were reported on marathon runners in a farther past. The $\dot{V} \mathrm{O}_{2 \max }$ of two top-level Kalenjins of the 1960s was higher than $80 \mathrm{ml} \mathrm{min}^{-1} \mathrm{~kg}^{-1}$ (Saltin and Åstrand 1967), and similar values were also observed in top-level Caucasians studied in the same period (di Prampero et al. 1970; Pollock 1977; Saltin and Åstrand 1967). Such high $\dot{V} \mathrm{O}_{2 \max }$ values have not been observed anymore in marathon runners in recent years, since values below $75 \mathrm{ml} \mathrm{min}^{-1} \mathrm{~kg}^{-1}$ are most commonly found at sea level nowadays (Billat et al. 2001; Larsen et al. 2004). It is noteworthy, however, that in older studies graded protocols were used and it was reported that the former provide $\dot{V} \mathrm{O}_{2 \max }$ values that are $5 \%$ higher than with the latter exercise mode (Hermansen and Saltin 1969). An extremely high $\dot{V} \mathrm{O}_{2 \max }$ is not a distinctive characteristic of contemporary marathon runners, independent of the ethnic group to which they belong.

Sustainable fraction of maximal oxygen consumption

A direct determination of $F_{\mathrm{d}}$ is complex, since it requires running until exhaustion at several submaximal speeds, and no previous study reported measured $F_{\mathrm{d}}$ values, but only estimates. The same was the case for the present athletes. In this study, we relied on the concept that the $F_{\mathrm{d}}$ sustained over a marathon $\left(F_{\text {mar }}\right)$ is directly related to $v_{\theta \text { an }}$ (Helgerud et al. 1990; Helgerud 1994), whose ratio to $v_{\max }$ is equal to $F_{\theta \text { AN }}$. So, we computed $F_{\text {mar }}$ from $F_{\theta \text { an }}$, according to Helgerud (1994). An indirect and simple comparison, 
however, is possible with the estimates provided by Saltin's linear formula (Saltin 1973), which, for a 2-h duration exercise, predicts $F_{\mathrm{d}}$ values of 0.81 , very close to the present $F_{\text {mar }}$. These $F_{\text {mar }}$ values, however, are not representative of what occurs during actual competitions. The ratio of the average running speed of the best marathon performance of present athletes to their $v_{\max }$ at sea level turns out to be equal to $0.929 \pm 0.057$ in $\mathrm{KA}$ and $0.919 \pm 0.050$ in EC (those with a marathon performance, $p=0.670$ ), which are all significantly higher than the corresponding $F_{\text {mar }}$. This would indicate that top-level marathon runners, whether Kalenjin or European, are capable of sustaining a higher fraction of the $v_{\max }$ over a 2$\mathrm{h}$ duration effort than that estimated after previous studies (Costill et al. 1973; di Prampero et al. 1986; Helgerud 1994; Helgerud et al. 1990).

\section{Energy cost of running}

The $C_{\mathrm{r}}$ was, as expected (Bunc and Heller 1989; di Prampero 1986; Jones and Doust 1996; Joyner 1991; Minetti et al. 2002), some $15 \%$ lower than usually found in the normal population and apparently similar to that reported in other studies on competitive runners (di Prampero et al. 1986; Lacour et al. 1990). Others observed higher $C r$ values in top-level marathon runners (Billat et al. 2001): those authors did not provide an interpretation of their high $C_{\mathrm{r}}$, but they reported that they found a positive correlation between $\dot{V} \mathrm{O}_{2 \max }$ and $C_{\mathrm{r}}$.

The present $C_{\mathrm{r}}$ values were affected by the fact that the present experiments were performed at altitude, where air resistance is less than at sea level, although the effects of air resistance during running are often neglected. In fact, $C_{\mathrm{r}}$ is generally considered invariant in a given individual and thus independent of the running speed (di Prampero 1986; Dill 1965; Hagberg and Coyle 1984; Margaria et al. 1963; McMiken and Daniels 1976; Minetti et al. 2002). On this basis, a simple method for the assessment of $C_{\mathrm{r}}$ in unsteady-state conditions was recently proposed (di Prampero et al. 2009). The concept of invariant $C_{\mathrm{r}}$ with speed stems from data essentially obtained during treadmill running. Pugh (1970) demonstrated that there was a fraction of $C_{\mathrm{r}}$ that increased with the square of wind velocity, although this fraction was quantified as being small (at most, $8 \%$ of $C_{\mathrm{r}}$ ). Following his study, the concept that an invariant $C_{\mathrm{r}}$ could be slightly higher during track running than during treadmill running was nevertheless admitted (di Prampero 1986; Jones and Doust 1996; Léger and Mercier 1984). If this is so, the effects of air resistance on $C_{\mathrm{r}}$ become larger as the running speed is higher. In this study, we had submaximal running speeds of $18 \mathrm{~km} \mathrm{~h}^{-1}$ in all subjects, of $20 \mathrm{~km} \mathrm{~h}^{-1}$ in some, so that higher submaximal speeds than in previous studies were investigated during track running, and a larger span of speeds was encompassed. It is thus not surprising that $C_{\mathrm{r}}$ was significantly higher at 18 than at $12 \mathrm{~km} \mathrm{~h}^{-1}$ in both groups. This is a clear effect of increased air resistance: in fact, Helgerud et al. (2010) found no differences in $C_{\mathrm{r}}$ as a function of speed during treadmill running at similar speeds to those of the present study.

The total energy cost of running on flat terrain $\left(C_{\mathrm{r}}\right)$ is the sum of the energy cost against aerodynamic forces $\left(C_{\mathrm{a}}\right)$ and the energy cost to override non-aerodynamic forces $\left(C_{\mathrm{na}}\right)$. As in any locomotion mode, the former increases with the square of speed; the latter is independent of speed. So, we can write:

$C_{\mathrm{r}}=C_{\mathrm{a}}+C_{\mathrm{na}}=k v^{2}+C_{\mathrm{na}}$

where constant $k$ is directly proportional to the projection area on the frontal plane, the air density and the drag coefficient, and inversely proportional to the apparent mechanical efficiency of running (di Prampero 1986; Ferretti et al. 2011). According to Eq. 3, if we plot $C_{\mathrm{r}}$ as a function of the square of speed, a linear relation is obtained, with slope equal to $k$ and $y$-intercept equal to $C_{\text {na }}$. This was done in Fig. 1 for the two investigated groups. The obtained values of $k$ are very close to those reported for traditional cycling (di Prampero 2000). This indicates that the differences in $C_{\mathrm{a}}$ between running and cycling are solely due to differences in speed, which is much higher in the latter than in the former, possibly due to lower $C_{\text {na. }}$. Constant $k$ turned out higher than estimated by di Prampero (di Prampero 1986) for running, a difference that may depend on a hypothetical underestimation of projection area in this case.

Non-aerodynamic forces, by contrast, resulted in being much higher than in cycling, as expected (di Prampero 1986; Ferretti et al. 2011), but lower than the estimate made by di Prampero (1986) for untrained non-professional runners. Non-aerodynamic forces should correspond to $C_{\mathrm{r}}$, independent of speed, determined during treadmill running. This being the case, the similarity of our $C_{\mathrm{r}}$ values with those of Lacour et al. (1990) should be reconsidered, in view of the fact that the latter was a treadmill study. Looking at $C_{\text {na }}$ suggests that the present top-level runners might indeed have a lower $C_{\mathrm{r}}$ on the treadmill than the runners investigated by others (Lacour et al. 1990; Padilla et al. 1992).

The $C_{\text {na }}$ and $k$ values provided by the regression equations of Fig. 1 are overall mean values for each group. Analysis of covariance showed no differences between the two regression lines, and coherently no significant differences in $C_{\mathrm{r}}$ were found between $\mathrm{KA}$ and EC. However, since $C_{\text {na }}$ (i) contributes to most of the $C_{\mathrm{r}}$ in running, (ii) is independent of speed and (iii) is affected by large intersubject variability, we may then assume that the lack of 
significant differences in $C_{\mathrm{r}}$ among groups and the relatively low correlation coefficients of the regression lines reported in Fig. 1 are mostly due to variability of $C_{\text {na }}$. Inter-subject variability of $C_{\text {na }}$ implies vertical shifts up or down of the individual $C_{\mathrm{r}}$ versus $v^{2}$ lines with respect to the corresponding regression line shown in Fig. 1. This shift can be estimated for each speed from the ratio between the individual $C_{\mathrm{r}}$ and the mean $C_{\mathrm{r}}$ at the same speed, when individual $C_{\text {na }}$ was obtained. Then the individual $C_{\mathrm{a}}$ was calculated as $C_{\mathrm{r}}$ minus the corresponding $C_{\text {na }}$. These results, however, still include the variability due to the different altitudes at which the experiments were carried out. Thus, $C_{\mathrm{a}}$ was referred to sea-level condition, by correcting it for the effects of lower air density at altitude. To this aim, the relationship between air density and altitude established by Capelli and di Prampero (1995) was used. The results of this analysis are shown in Fig. 2, showing that at each speed $\mathrm{KA}$ and $\mathrm{EC}$ had also equal $C_{\mathrm{a}}$ values ( $p$ ranging from 0.131 at $12 \mathrm{~km} \mathrm{~h}^{-1}$ to 0.378 at $18 \mathrm{~km} \mathrm{~h}^{-1}$ ). To sum up, the lack of differences in $C_{\mathrm{r}}$ between KA and EC is not only a result of a confounding effect of the predominance of highly variable $C_{\text {na }}$ in determining $C_{\mathrm{r}}$ : KA and EC have the same $C_{\text {na }}$ and the same $C_{\mathrm{a}}$, indeed.

\section{Best performance in marathon running}

The knowledge of sea-level $\dot{V} \mathrm{O}_{2 \max }, C_{\mathrm{r}}$ and $F_{\mathrm{d}}$ allows an estimate of the mean marathon running speed for a

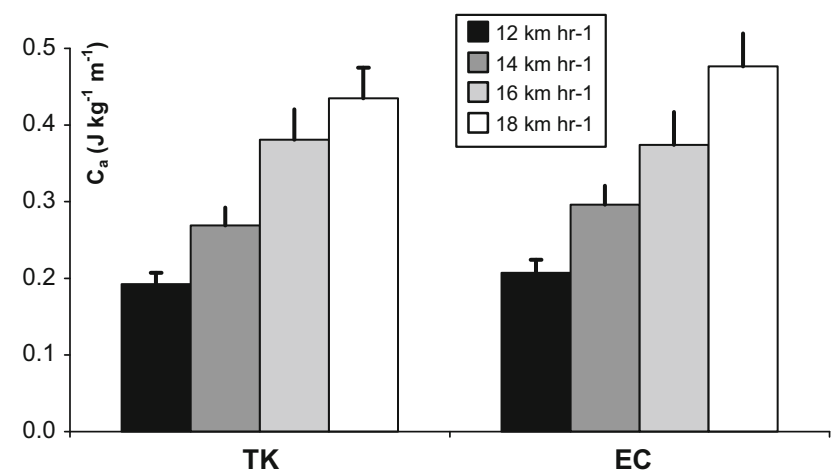

Fig. 2 Estimated aerodynamic energy $\operatorname{cost}\left(C_{\mathrm{a}}\right)$ of running at the indicated speeds for top-level Kalenjin (KA) and European controls (EC). No significant differences were found between KA and EC

comparison with actual running speeds as attained during competition. The estimated data at sea level used for this prediction are summarized in Table 4 . When $F_{\text {mar }}$ is used as index of $F_{\mathrm{d}}$, significantly lower predicted than actual marathon speeds are obtained. When $F_{\theta \text { AN }}$ is used instead, predicted speeds are much closer, although still lower, to actual speeds, in both groups. This discrepancy is at least partly related to the fact that athletes run a marathon at their best physical condition, at an even higher $F_{\mathrm{d}}$ than the $F_{\theta \text { AN }}$. However, it is of note that we took the individual best performance as actual marathon speed. The above differences are further reduced if we consider the marathon performances that some of the athletes established within 3 months after their participation in the tests. Let us take

Table 5 Individual data obtained on two KA and one EC athletes, who accepted to disclose their data and who ran a marathon within 3 months after testing

\begin{tabular}{|c|c|c|c|c|c|c|}
\hline & \multicolumn{2}{|c|}{ Martin Lel } & \multicolumn{2}{|c|}{ Elijah Keitany } & \multicolumn{2}{|c|}{ Viktor Röthlin } \\
\hline & Eldoret & SL & Ortisei & SL & Eldoret & SL \\
\hline$V^{\prime} \mathrm{O}_{2 \max }\left(1 \min ^{-1}\right)$ & 3.67 & 3.94 & 4.40 & 4.63 & 3.63 & 3.90 \\
\hline$V^{\prime} \mathrm{O}_{2} \max \left(\mathrm{ml} \mathrm{min} \min ^{-1} \mathrm{~kg}^{-1}\right)$ & 62.8 & 67.5 & 64.0 & 67.4 & 59.1 & 63.5 \\
\hline$v_{\max }\left(\mathrm{m} \mathrm{s}^{-1}\right)$ & 5.444 & 5.854 & 5.611 & 5.969 & 5.556 & 5.974 \\
\hline$C_{\mathrm{r}}$ at $5 \mathrm{~m} \mathrm{~s}^{-1}\left(\mathrm{~J} \mathrm{~kg}^{-1} \mathrm{~m}^{-1}\right)$ & 3.28 & 3.39 & 3.37 & 3.45 & 3.49 & 3.64 \\
\hline$v_{\Theta A N}\left(\mathrm{~m} \mathrm{~s}^{-1}\right)$ & 5.139 & 5.526 & 5.097 & 5.422 & 5.361 & 5.765 \\
\hline$F_{\mathrm{\Theta AN}}$ & 0.944 & 0.944 & 0.908 & 0.908 & 0.965 & 0.965 \\
\hline \multirow[t]{3}{*}{$v_{\operatorname{mar}}$ at $\mathrm{SL}\left(\mathrm{m} \mathrm{s}^{-1}\right)$} & Predicted & 5.762 & & 5.513 & & 5.550 \\
\hline & Actual & 5.508 & & 5.438 & & 5.480 \\
\hline & Record & 5.615 & & 5.551 & & 5.521 \\
\hline
\end{tabular}

$S L$ sea level, $\dot{V} \mathrm{O}_{2 \max }$ maximal oxygen consumption, $v_{\max }$ maximal aerobic speed, $C_{r}$ energy cost of running, $v_{\Theta A N}$ speed at the lactate threshold, $F_{\Theta A N}$ sustainable fraction of $\dot{V} \mathrm{O}_{2 \max }$ calculated after $v_{\Theta A N}, v_{\text {mar }}$ mean speed over a marathon, predicted speed after Eq. 1, actually sustained speed within 3 months after testing, and personal record speed. On 22 April 2007, Lel won the London Marathon in $2 \mathrm{~h} 7$ min and $41 \mathrm{~s}$ running at a mean speed of $5.508 \mathrm{~m} \mathrm{~s}^{-1}$, i.e., $4.4 \%$ slower than predicted. According to the prediction, he would have in principle been able to run in $2 \mathrm{~h}$ 2 min and 3 s, i.e., faster than the current world record, but he did not need to exploit such a potential to gain the London marathon. On the contrary, on 31 October 2010, Keitany was eighth in Frankfurt, Germany, in $2 \mathrm{~h} 9 \mathrm{~min}$ and $19 \mathrm{~s}$, with a mean speed of $5.438 \mathrm{~m} \mathrm{~s}^{-1}$, equivalent to only $1.36 \%$ less than the predicted speed. His best performance on the marathon $(2 \mathrm{~h} 6 \mathrm{~min} 41 \mathrm{~s})$ is only $0.69 \%$ faster than our prediction $(2 \mathrm{~h}$ $7 \mathrm{~min}$ and $33 \mathrm{~s}$ ). On 1 April 2007, Röthlin won the Zürich marathon in $2 \mathrm{~h} 8 \mathrm{~min}$ and $20 \mathrm{~s}$. His mean speed was $1.24 \%$ less than the predicted speed. His best performance ( $2 \mathrm{~h} 7 \mathrm{~min}$ and $23 \mathrm{~s}$ ) is only $0.52 \%$ slower than our prediction $(2 \mathrm{~h} 6 \mathrm{~min}$ and $43 \mathrm{~s})$ 
three examples, from two KA and one EC who authorized disclosure of their individual data, Martin Lel, Elijah Keitany and Viktor Röthlin. Lel and Röthlin were tested in Eldoret, Kenya, in February 2007, Keitany in Ortisei, Italy, in July 2010. Their results are shown in Table 5. Their predicted marathon speeds, calculated using $F_{\theta \text { an }}$, were $20.74 \mathrm{~km} \mathrm{~h}^{-1}$ for Lel, $19.85 \mathrm{~km} \mathrm{~h}^{-1}$ for Keitany and $19.98 \mathrm{~km} \mathrm{~h}^{-1}$ for Röthlin, to be compared, respectively, with record speeds of $20.21,19.98$ and $19.87 \mathrm{~km} \mathrm{~h}^{-1}$.

The present results are not in contrast with the hypothesis that shortly the 2-h record in the marathon may be broken (Capelli and Ferretti 2011), possibly by an athlete with an extremely low $C_{\mathrm{r}}$ (Joyner 1991; Foster and Lucia 2007). In $\mathrm{KA}$, the coefficient of variability of sea-level $\dot{V} \mathrm{O}_{2 \max }$ was $8.62 \%$, that of $C_{\mathrm{r}}$ at $18 \mathrm{~km} / \mathrm{h}$ was $9.05 \%$, and that of $F_{\theta \text { an }}$ $6.08 \%$. Assume a hypothetical athlete with a higher $\dot{V} \mathrm{O}_{2 \max }$ and $F_{\theta \text { AN }}$ and a lower $C_{\mathrm{r}}$ at $18 \mathrm{~km} \mathrm{~h}^{-1}$ than the mean values of the KA group by an amount corresponding to one-half of the coefficient of variation of KA for each variable, a very likely case indeed. Well, such an athlete would in theory be able to run the marathon in $2 \mathrm{~h} 0 \mathrm{~min}$ and $14 \mathrm{~s}$, indicating that the goal of the 2-h marathon is close indeed.

\section{Conclusions}

In conclusion, top-level Kalenjin marathon runners are characterized by a high, but not very high, $\dot{V} \mathrm{O}_{2 \max }$, an extremely elevated $F_{\mathrm{d}}$ and a low $C_{\mathrm{r}}$. The same, however, was the case for their European counterparts, so that the dominance of Kenyan marathon runners with respect to Caucasians cannot be explained by differences in the energetics of running. The predictions of mean running speed that can be made from the present data are reasonably close to the actual running performances, if an $F_{\mathrm{d}}$ equal to the $F_{\theta \mathrm{AN}}$ is accounted for, although the $F_{\mathrm{d}}$ actually sustained during a competition might be somewhat higher than $F_{\theta \mathrm{AN}}$. A precise knowledge of the individual energetic parameters is still a crucial aspect for the evaluation of the physical condition of a marathon runner in view of a competition. The 2-h marathon record is not far from being achieved.

Acknowledgments Financial support to this work was provided by a grant the Office Federal du Sport, Magglingen, Switzerland, to Guido Ferretti. We are grateful to Rosa Associati srl, Iseo, Italy, and the Italian Athletic Federation (FIDAL) for collaboration in athletes' recruitment and for logistic support.

\section{References}

Billat VL, Demarle A, Slawinski J, Paiva M, Koralsztein JP (2001) Physical and training characteristics of top-class marathon runners. Med Sci Sports Exerc 33:2089-2097
Billat V, Lepretre PM, Heugas AM, Laurence MH, Salim D, Koralsztein JP (2003) Training and bioenergetic characteristics in elite male and female Kenyan runners. Med Sci Sports Exerc 35:297-304

Bunc V, Heller J (1989) Energy cost of running in similarly trained men and women. Eur J Appl Physiol 59:178-183

Capelli C, di Prampero PE (1995) Effects of altitude on top speeds during $1 \mathrm{~h}$ unaccompanied cycling. Eur J Appl Physiol 71:469-471

Capelli C, Ferretti G (2011) Comments on viewpoint: the two-hour marathon: who and when? Physiological determinants of best performance in marathon running. J Appl Physiol 110:283-284

Coetzer P, Noakes TD, Sanders B, Lambert MI, Bosch AN, Wiggins T, Dennis SC (1993) Superior fatigue resistance of elite black South African distance runners. J Appl Physiol 75:1822-1827

Costill DL, Thomas H, Roberts E (1973) Fractional utilization of the aerobic capacity during distance running. Med Sci Sports 5:248-252

Dempsey JA, Wagner PD (1999) Exercise-induced arterial hypoxemia. J Appl Physiol 87:1997-2006

Dempsey JA, Hanson PG, Henderson KS (1984) Exercise-induced arterial hypoxaemia in healthy human subjects at sea level. J Physiol Lond 355:161-175

di Prampero PE (1986) The energy cost of human locomotion on land and in water. Int J Sports Med 7:55-72

di Prampero PE (2000) Cycling on earth, in space, on the moon. Eur J Appl Physiol 82:345-360

di Prampero PE, Piñera-Limas F, Sassi G (1970) Maximal muscular power, aerobic and anaerobic, in 116 athletes performing at the XIXth Olympic games in Mexico. Ergonomics 13:665-674

di Prampero PE, Atchou G, Bröckner JC, Moia C (1986) The energetics of endurance running. Eur J Appl Physiol 55:259-266

di Prampero PE, Salvadego D, Fusi S, Grassi B (2009) A simple method for assessing the energy cost of running during incremental tests. J Appl Physiol 107:1068-1075

Dill DB (1965) Oxygen used in horizontal and grade walking and running on the treadmill. J Appl Physiol 20:19-22

Ferretti G (1990) On maximal oxygen consumption in hypoxic humans. Experientia 46:1188-1194

Ferretti G, Moia C, Thomet JM, Kayser B (1997) The decrease of maximal oxygen consumption during hypoxia in man: a mirror image of the oxygen equilibrium curve. J Physiol Lond 498:231-237

Ferretti G, Bringard A, Perini R (2011) An analysis of performance in human locomotion. Eur J Appl Physiol 111:391-401

Foster C, Lucia A (2007) Running economy: the forgotten factor in elite performance. Sports Med 37:316-319

Hagberg JM, Coyle EF (1984) Physiological comparison of competitive race walking and running. Int J Sports Med 5:74-77

Helgerud J (1994) Maximal oxygen uptake, anaerobic threshold and running economy in women and men with similar performances level in marathons. Eur J Appl Physiol 68:155-161

Helgerud J, Ingjer F, Strømme SB (1990) Sex differences in performance-matched marathon runners. Eur J Appl Physiol 61:433-439

Helgerud J, Støren O, Hoff J (2010) Are there differences in running economy at different velocities for well-trained distance runners? Eur J Appl Physiol 108:1099-1105

Hermansen L, Saltin B (1969) Oxygen uptake during maximal treadmill and bicycle exercise. J Appl Physiol 26:31-37

Jones AM, Doust JH (1996) A 1\% treadmill grade most accurately reflects the energetic cost of outdoor running. J Sports Sci 14:321-327

Joyner MJ (1991) Modelling optimal marathon performance on the basis of physiological factors. J Appl Physiol 70:683-687

Kleinbaum DG, Kupper LL, Muller KE (1987) Applied regression analysis and other multivariable methods. PWS-KENT Publishing Company, Boston 
Lacour JR, Padilla-Magunacelaya S, Barthélémy JC, Dormois D (1990) The energetics of middle distance running. Eur J Appl Physiol 60:38-43

Larsen HB (2003) Kenyan dominance in distance running. Comp Biochem Physiol A 136:161-170

Larsen HB, Christensen DL, Nolan T, Søndergaard H (2004) Body dimensions, exercise capacity and physical activity level of adolescent Nandi boys in western Kenya. Ann Hum Biol 31:159-173

Léger L, Mercier B (1984) Gross energy cost of horizontal treadmill and track running. Sports Med 1:270-277

Margaria R, Cerretelli P, Aghemo P, Sassi G (1963) Energy cost of running. J Appl Physiol 18:367-370

McMiken DF, Daniels JT (1976) Aerobic requirements and maximum aerobic power in treadmill and track running. Med Sci Sports 8:14-17

Minetti AE, Moia C, Roi GS, Susta D, Ferretti G (2002) Energy cost of walking and running at extreme uphill and downhill slopes. J Appl Physiol 93:1039-1046

Onywera VO, Kiplamai FK, Boit MK, Pitsiladis YP (2004) Food and macronutrient intake of elite Kenyan distance runners. Int J Sport Nutr Exerc Metab 14:709-719

Onywera VO, Scott RA, Boit MK, Pitsiladis YP (2006) Demographic characteristics of elite Kenyan endurance runners. J Sports Sci 24:415-422

Padilla S, Bourdin M, Barthélémy JC, Lacour JR (1992) Physiological correlates of middle-distance running performance. A comparative study between men and women. Eur J Appl Physiol 65:561-566

Pollock ML (1977) Submaximal and maximal working capacity of elite distance runners. Part I: cardiorespiratory aspects. Ann NY Acad Sci 301:310-327
Prommer N, Thoma S, Quecke L, Gutekunst T, Völzke C, Wachsmuth N, Niess AM, Schmidt W (2010) Total hemoglobin mass and blood volume of elite Kenyan runners. Med Sci Sports Exerc 42:791-797

Pugh LGCE (1970) Oxygen intake in track and treadmill running with observations on the effect of air resistance. J Physiol Lond 207:823-835

Saltin B (1973) Oxygen transport by the circulatory system during exercise in man. In: Keul $\mathrm{J}$ (ed) Limiting factors of physical performance. Thieme, Stuttgart, pp 235-252

Saltin B, Åstrand PO (1967) Maximal oxygen uptake in athletes. J Appl Physiol 23:353-358

Saltin B, Kim CK, Terrados N, Larsen H, Svedenhag J, Rolf CJ (1995a) Morphology, enzyme activities and buffer capacity in leg muscles of Kenyan and Scandinavian runners. Scand J Med Sci Sports 5:222-230

Saltin B, Larsen H, Terrados N, Bangsbo J, Bak T, Kim CK, Svedenhag J, Rolf CJ (1995b) Aerobic exercise capacity at sea level and at altitude in Kenyan boys, junior and senior runners compared with Scandinavian runners. Scand J Med Sci Sports 5:209-221

Wehrlin JP, Hallén J (2006) Linear decrease in $V \mathrm{O}_{2} \max$ and performance with increasing altitude in endurance athletes. Eur J Appl Physiol 96:404-412

Yang N, MacArthur DG, Wolde B, Onywera VO, Boit MK, Lau SY, Wilson RH, Scott RA, Pitsiladis YP, North K (2007) The ACTN3 R577X polymorphism in East and West African athletes. Med Sci Sports Exerc 39:1985-1988 